Postgraduate Training around the World

\title{
Medical organisation and training in Switzerland
}

\author{
G.B. Zulian*† \\ Department of Medicine, The Royal Marsden Hospital, Downs Road, Sutton, Surrey SM2 5PT, UK.
}

\begin{abstract}
Summary: This paper aims to report on a successful medical system in a very successful country, politically organized as a federal republic, which put 12 billion Swiss francs in its Health budget in 1980. It also reports on the training of Swiss physicians with special reference to internal medicine and emphasis on their independence. The benefit of close collaboration between the public and the private sector should appear obvious even if this situation might be jeopardized by too many new graduates for fewer patients.
\end{abstract}

\section{Introduction}

Switzerland is a very small country in the mid west of Europe with only six and a half million inhabitants. It is also supposed to be one of the richest in the world. About $80 \%$ of the population is SwissGerman speaking, 15\% French and the rest Italian and Romanche. As a federal republic, the country is politically divided into 26 independent counties, called cantons, every one with its local government responsible for local taxes, security, education and health. Each canton is in fact a country in itself with sometimes differences in some aspects of the law but each one also belongs to the Swiss Confederation. It has representatives in the two different and independent parts of the Federal Parliament, called Conseil National and Conseil des Etats, where the somewhat magic consensus is made, i.e. agreeing to take a decision even when interests appear discordant at first sight. The central government, called Conseil Federal, is responsible for the general organization and coordination in the whole country, and its seven members are elected within the five main and leading political parties of the country. When decisions have to be taken on any subject of importance, the entire population has to be consulted and vote on the subject and this occurs at least ten times per year.

Correspondence: G.B. Zulian, M.D.

Accepted: 20 January 1988.

${ }^{*}$ Dr Zulian is a recipient of an EORTC fellowship grant. $\dagger$ This paper is based on a talk given to the European Medical Research Group in London, 10 December 1987.

\section{Insurances system}

By law, $100 \%$ of the population is insured against accidents and about $\mathbf{9 8 \%}$ insure themselves against illnesses. The insurance system is private with local, national or international companies which are mostly subsidized by the government. Every citizen has to pay a monthly tax deductible premium to the company of his own choice. This premium represented $7.6 \%$ of his income in $1982 .{ }^{1}$ Providing he is not self-employed he will usually receive some support from his employer. There are three degrees of insurances, private, semi-private and public, but differences are only to be found in hospital accommodation, final bills and choice of doctor. Doctors in private practice are paid by the patient who then will claim his money back from the insurance company. A fixed fee though has to be paid by the patient himself as well as $10 \%$ of the drug's price. Doctors working exclusively in hospitals receive a salary from the hospitals which are then supported by both insurance companies and local communities via taxes. Local authorities, hospitals, doctors and insurance companies are supposed to have agreed on the cost of any technical act or medical intervention but neither minimal nor maximal charge is compulsory.

In 1980 , every single insured patient cost 886 Swiss francs to his insurance company which in return received about $25 \%$ of this amount from local and federal authorities, the remaining $75 \%$ being paid by the premiums. Overall, the cost of public health in Switzerland in 1980 was slightly more than 12 billion Swiss francs, of which $45 \%$ went to hospitals, $17 \%$ to doctors, $10 \%$ to dentists,

(C) The Fellowship of Postgraduate Medicine, 1988 
$14 \%$ to drugs, $5 \%$ to medical schools in the universities and $9 \%$ elsewhere, but representing only $6.9 \%$ of the gross national product. ${ }^{1}$

The ratio of doctor to inhabitants was 1:451 in 1980 and hospital beds 128 for 10,000 inhabitants. Both figures were at that time similar to West Germany $(1: 442$ and $115: 10,000)$ and Sweden $(1: 492$ and $161: 10,000)$ but almost twice as many compared to United Kingdom which had one doctor to every 808 inhabitants and only 78 beds for 10,000 people. $^{1}$ Therefore, in Switzerland, shortage of beds and waiting lists are virtually unknown.

\section{Training and its structure}

In 1984 , there were 8823 doctors of all specialties in independent private practice and 7146 in postgraduate training. ${ }^{2}$ This training is completed either in one of the five university hospitals or in some of the multiple district or private hospitals but more often fellows move from one hospital to another according to specific training rules. Only $9 \%$ of the available beds belong to the University Hospitals in Basel, Bern, Geneva, Lausanne or Zurich $^{1}$ but every single hospital is well equipped for any kind of emergency and will admit anybody if necessary. Specialized hospitals are an exception in Switzerland.

Every canton has its own independent medical organisation. ${ }^{3}$ The national Foederatio Medicorum Helveticorum (FMH) has 17,000 members which represents more than $90 \%$ of the practising doctors in the country. In Great Britain, the role of the FMH could be compared to that of the British Medical Association, the General Medical Council, the Royal Colleges and, to a certain extent, the medical defence organizations all put together. The FMH is responsible for the standard of both preand postgraduate training and also further quality control. It works in close connection with the political authority, the Federal Health Department, in order to plan and organise the management of Swiss health including vaccination, anti-smoking or any other kind of campaign. It is not, however, responsible for matters such as hospital management or funding for research and it is entirely controlled and run by doctors.

\section{Internal medicine as an example}

Out of almost 9000 practising doctors in 1984, 1847 specialized in internal medicine and so were recognized by adding the three letters FMH to their name. Furthermore, nine subspecialties of internal medicine are also recognized after appropriate training which has to be approved by the FMH: allergology/clinical immunology, endocrinology, gastroenterology, haematology, cardiology, nephrology, respiratory medicine, rheumatology ${ }^{2}$ and (from 1986) onco-haematology.

In 1984, 833 students graduated after six years spent in university on theoretical and practical subjects. Theory includes biology, physics, biochemistry, pathology and anatomy for the first two years called 'propédeutiques' with appropriate examination at the end of each one. Three years are then devoted to virtually all aspects of medicine before the last one is spent as a kind of houseman under senior registrar supervision or already doing some research. The finals comprise 17 examinations and these lead to the Federal Diploma of Medicine, delivered by the Federal Health Department, allowing one to work anywhere in the country providing local authorities and colleagues agree. The median age at time of graduation is about 26 years at which time it would already be theoretically possible to become independent. In the same year, 1984, 159 doctors completed their postgraduate training in internal medicine and were then recognized specialists-FMH in internal medicine. This training includes experience in almost every field of internal medicine with rotations organised between divisions of departments for at least four years. Selection of rotations is made depending upon availability and future prospects either by the fellow himself or as advised by senior registrars, consultants or professors. Furthermore at least one year must be spent in other disciplines like surgery, radiology, and pathology. To become a Doctor of Medicine a thesis must also have been written under a professor's supervision and accepted by one of the five Universities, the subject of it being either research or clinical work. Application can then be made to the board of the FMH which eventually delivers the qualification of specialist FMH in internal medicine. The introduction of examinations at the end of the training period in order to obtain the FMH qualification is currently under careful scrutiny and could well soon replace the board.

Also in the same year, 59 internists-FMH qualified as specialists-FMH in one of the recognized subspecialties of internal medicine. The training includes a minimum of two years spent in one of the few teaching hospitals approved by the FMH and similar examinations as above could also soon be introduced. Considering the organization of the Swiss system, it might be worth going abroad to referral hospitals to get more specialized training. In this respect and as everywhere else, funding remains a problem for doctors leaving the 
country for several years. Exchange schemes are few and Switzerland is neither a member of the United Nations nor of the European Economic Community which does not make things easier. Nevertheless the hospital in which the initial training has been completed and to which the fellow will eventually return can sometimes provide money along with some international or local organization. The National Fund for Scientific Research remains the most important source for funding providing that a research project has been settled.

Marked differences from other systems include the absence of specialized training hospitals. In Geneva University Hospital, which is the largest in Switzerland with a total amount of almost 2000 beds, there is one department of medicine divided into the University Medical Clinic and the Therapeutic Clinic, each one with its own professor having 100-200 beds under his care (Table I). These clinics are divided further into wards of 20 beds under senior registrar supervision which has one senior house officer, one houseman and one or two students as members of the staff. Again, the wards are not specialized, but linked to the department there are many sections led by a consultant or a professor who do not usually have their own beds but who are closely involved in the management of the patients for advice, specialized tests and treatment. There is, in addition, an outpatient and casualty department which can also be considered as a section. The postgraduate training is first done by working in the general ward and then by rotating in the specialized

Table I Schematic diagram of Geneva University Hospital organization.

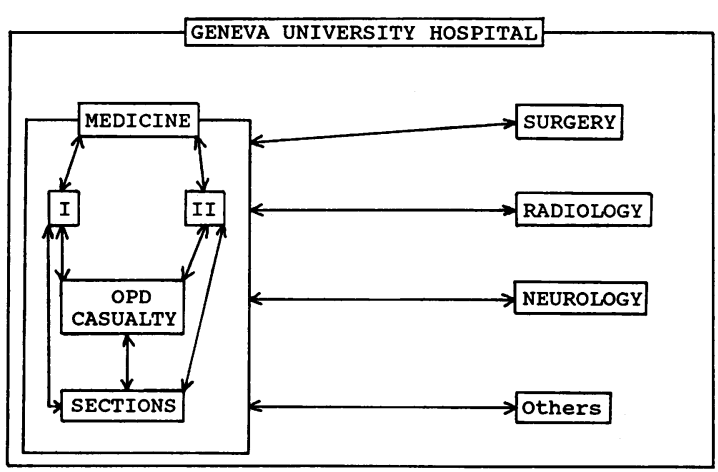

I=Medical Clinic; II = Therapeutic Clinic; OPD = outpatient department; SECTIONS = cardiology, respiratory medicine, endocrinology, infectious disease, oncology, haematology, nephrology, immunology, allergology, dermatology, etc.; Others = ophthalmology, gynaecology and obstetrics, paediatrics, ENT, etc. sections. The further specialization is then done in the appropriate section. Other university hospitals in other counties might be organized differently but will basically offer the same facilities.

At the end of any training, the vast majority of doctors will have to become independent, willingly or not. Seven hundred and fifteen, including general practitioners, did so in 1984 . In the particular case of a 'general internist', that is specialist-FMH in internal medicine, the median time from graduation was about seven years during which he could well have been through various grades from houseman to consultant. Starting one's own practice means obviously an office, technical facilities and a secretary. Again money is the key and so far banks have been very pleased to lend it. Since advertising is not permitted, the first months or even years can be very difficult. Often though, there is the possibility for collaboration at a consultant level with private, district or even teaching hospitals. Highly specialized or very well trained doctors will sometimes remain attached to an hospital as consultants or heads of divisions or departments. A minority will return or continue their research, working either for university hospitals or private concerns such as drug companies. Some will be in a position to combine research and clinical work and will usually becomes heads of units, departments or sections and sometimes professors of a university.

\section{Conclusions}

Such an original system has been very successful indeed in Switzerland, producing a high level of care throughout the country. The private and public sectors are always closely linked together and also work together, hopefully for their mutual benefit. One must emphasize that shortage of money does not really exist in this system which remains basically private, independent and matches the political federal organization of the whole country on a democratic basis.

The future of the medical profession appears to depend upon the maintenance of the wealth of the country but also upon the arrival of many students into the so-called market as this is putting up the general costs of medicine, causing some unemployment in young physicians and making it more difficult to start private practice because of a lack of patients. Without reducing the number of graduates, perhaps by the introduction of the unpopular 'numerus clausus', the situation is unfortunately likely to deteriorate markedly in the next five or ten years. This will certainly happen at the patient's expense but could also result in more political control of our, so far, truly independent profession. 


\section{References}

1. Service d'information des maisons de recherche pharmaceutique Ciba-Geigy, Roche et Sandoz. La santé publique en Suisse: prestations, coûts, prix. Pharma Information, Bâle, Suisse, 1984.

2. Secréteriat général des institutions du corps médical suisse. Statistique 1984 des membres de la fédération des médecins suisses. Bulletin des médecins suisses 1986, 67: $176-186$
3. Secrétariat général des institutions du corps médical suisse. Nous travaillons pour vous. Bulletin des médecins suisses 1983, 64: 35-45. 